\title{
The City Experience with Location-Based Media: An Examination Through Cognitive Maps
}

\author{
Ayșenur Hilal Iavarone ${ }^{1}$, Esin Hasgül2 ${ }^{\odot}$ \\ ${ }^{1}$ Res. Asst., Faculty of Architecture, Istanbul Kultur University, Istanbul, Turkey. (Principal contact for editorial \\ correspondence), Email: h.binici@iku.edu.tr \\ ${ }^{2}$ Assist. Prof. Dr., Faculty of Architecture, Istanbul Kultur University, Istanbul, Turkey. Email: e.hasgul@iku.edu.tr
}

\begin{abstract}
Purpose

The physical space has been an important value for supporting human experience. With the development of mobile devices and location-based media, these technologies have been increasingly present in our virtual spatial experience and the experience of physical city has been changed permanently. Accordingly, this paper aims to discuss the experience potential of urban space with location-based technologies.

Design/Methodology/Approach

The research structure of this study is based on the literature of location-based media and 'Space of flow' theory. Within the methodology, a workshop is conducted to review the cognitive mappings of the virtual city experience. The workshop is structured through two segments: Documenting the spatial experience revealed using location-based media made by cognitive mappings and testing participants' direct experiences within structured questionnaire-based interviews and finally, interpretating of the obtained data.

Findings

This paper provides an experiential examination of the relationship between the usage of the degree of location-based media and cognitive experience. Findings point out that experience may differ depending on the media interface used and it is controversial comparing with the physical space experience with its multiple relationships.

\section{Research Limitations/Implications}

The research subject had been exemplified with limited location-based media in a specific location.

Originality/Value

The proposed method of examining the degree of spatial experience by the location-based media linking with interviews determines the originality of the study. There are also limited studies on the topic of location-based media by focusing on the users' cognitive maps.
\end{abstract}

Keywords: Urban space, virtual city experience, spatial cognition, location-based media, cognitivemapping 


\section{INTRODUCTION}

Location-based media (LBM), which establish a connection between physical and digital spaces, differentiate as a functional communication channel that connects the communication media to space and the space to the user's mobile devices. This function allows citizens to communicate with the city with the help of digital interfaces (Ozkul \& Gauntlett, 2014; Tokgöz, 2017). Especially in the process of the rapid evolution of social media after 2005, the spread of location-based media started to include media as a new area where users experience the city in space experience research (De Souza e Silva \& Sutko, 2010; Gordon \& de Souza e Silva, 2011; Humphreys, 2007; Humphreys \& Liao, 2013). There is a growing body of literature on location-based media and its spatial experience. The impacts of LBM on individuals' everyday experience of place (Wilken, 2012), LBM impact of social life on urban space (Gordon \& de Souza e Silva, 2011; Sheller \& Urry, 2006; Wilken, 2012), and memory and cognition effect of LBM (De Souza e Silva \& Hjorth, 2009; Ozkul, 2013; Ozkul \& Gauntlett, 2014; Saker \& Evans, 2016b) has been explored in many studies.

The goals of this area of research are to explore and understand the impacts of LBM and the possible urban interactions. The current study seeks to contribute to this field by exploring the following research questions:

(I) Is it possible to experience a city that has not been physically visited through location-based technologies? (II) How can the spatial perception of a city visited with location-based media be visible in cognitive mapping? (III) Which media tools shape this experience and how? (IV) What are the limitations of a media-based venue experience?

It is possible to come across similar research questions in the literature. More and more architectural scholars attempt to well define and interpret the nature of media-based spatial experience (Akgun Yuksekli, 2017; Iavarone \& Dursun Çebi, 2019; Kut et al., 2013). However, these researches are limited by the exploration of space without considering spatial cognition theories background. In order to conceptualize the new spatial experience of LBM impact, this research follows the path of the cognitive mapping studies of spatial behaviour theory and thus seeks to make a contribution to the studies on the spatial experience of LBM.

In the digitalized world era, the city can be discussed as a platform in which image datasets are collected, stored, and shared. According to this scenario, the participants feel they were actually in the place, however with no actual existence in space through location-based media platforms. The present paper tests this hypothesis by applying cognitive mapping methodology.

The article is divided into three parts. The first part introduces the definition of LBM and the theoretical background of media-space studies. After a short review of the literature, the second part focuses on the case study of the structured workshop to explore research questions. The outputs of the workshop, in which cognitive mapping 
The City Experience with Location-Based Media: An Examination Through Cognitive Mappings

was used as a method, were evaluated within the framework of the research questions in two segments: Evaluation of cognitive maps and interviews. In the last section, workshop outputs are interpreted with critical reading. Based on the findings of the case study conducted with the workshop, it can be concluded that LBM has a significant effect on the city even when physical space is not included in the experience. On the other hand, the outputs of the study also show the shortcomings of a virtual visit to a city that is not physically visited, space can only be experienced through images, so the exploration cannot be internalized. The findings of the study also help to read the different forms of experience created by different LBM uses. In this context, the study reveals that the use of LBM is included in spatial experience studies as a new interface in human-environment interaction. In the following section, the conceptual framework surrounding the present research will be outlined, beginning with a discussion of LBM and its impact on the urban spatial experience.

\section{THEORETICAL BACKGROUND}

\section{Redefining the Concept of Space Transformed with Media}

Since the beginning of computer evolution, a body of research analyzes how media interfaces mediate the relationship between technology use and physical spaces. Manuel Castells (1996), one of the pioneers of this literature, has defined the new system that has been structured by technology, with networks and connections. Since "everyone" and "everywhere" are connected all the time, inevitably, the concept of space and time has also changed. Castells (1996) suggests that space becomes connected. He defined this spatial transformation with the concept of "space of flow" which represents "the material arrangements that allow for the simultaneity of social practices without territorial contiguity" (Castells, 1996, p. 294). He emphasizes that electronic networks interact with space and new dynamics of the spatial experiences that occur with technology. Thus, the understanding of static space began to be replaced by the "fluid space" concept with the effect of technology.

Starting from the perspective that Castells brought to the subject, many questions can be asked to define the unique relationship of the redefined society with space. What happens to space when anyone can go anywhere anytime through the Internet? What will be the experience of the new situation of the space? The context of these questions has changed, especially with the rapid inclusion of mobile and GPS technology in everyday life. Since location-based technologies had started to be part of daily life, they have started to change the way we interact with the place on a daily basis. These technologies have the potential to create new layers of seeing. Therefore, it can be assumed that the way we see the urban context that we live in, and the concept of space is under significant transformation. With the use of LBM, is it possible to talk about "space of flows" for urban experience through Internet networks as Castells suggested? Can LBM create enough realistic atmosphere for urban space experience? Focused on these questions, this article focuses on LBM and the area of research it creates in the following section. 


\section{Location-Based Media (LBM) as a Spatial Experience Tool}

In a society where technology plays an essential role and creates new experiences, as a major distinctive, media usage identifies the new concepts of spatial experience: location-based media (LBM) usage and its effects on the space (Iavarone \& Dursun Çebi, 2019). Within the impact of new media, being online, being visible, and being reachable is the new concept of urban life. Therefore, being in "somewhere" and interacting with the location through mobile devices is essential to be connected to the network.

LBM can be described as mobile device applications that allow users to share their locations and see other's locations (check-in) through their new media networks (De Souza e Silva \& Frith, 2010). Location-based media services, such as Foursquare, Facebook Place, Instagram Location, Google Maps, TripAdvisor, help users to share their location data with other users. By doing so, users can find locations, places, and people as well as they can be found too. In other words, people let technology track them in order to have location information.

There has been a growing literature and ongoing debate about this new concept in a variety of scientific fields. LBM has been studied as a personal memory tool (Frith, 2014, p. 2), as an urban locative game (De Souza e Silva, 2006; Humphreys, 2007; Saker \& Evans, 2016a; Tokgöz, 2017), as the visualization of space (De Souza e Silva \& Sutko, 2011) and as a coordinator of social interactions (Frith, 2014). Researchers such as Humphreys (2010), De Souza e Silva \& Frith (2010), Ozkul (2013), Evans $(2014,2015)$, focused on the different impact of location-based media on spatial experience and urban knowledge and found that location-based media can be an interactive, personal, and informative way of connecting for individuals in terms of spatial experience. They emphasized that location-based technologies create spatial awareness, rearrange social urban habits, and allow individuals to create their own re-narratives of the city. In the literature, it is possible to encounter different studies that argue that LBM increases the individual urban experience and facilitates the establishment of new relationships between the individual and the space.

Gordon \& de Souza e Silva (2011), open a debate on an essential question: why location is still a matter if we are experiencing today's society in which everyone is connected with everywhere virtually? They have explained location-aware technologies changing our perception of urban life and LBM's location is a way to be connected through information and shared experience. Saker \& Frith (2018), emphasize the impact of locative media networks on urban life, specifically to coordinate everyday life. As mobile devices and new media connect individually constantly, location-based media connects individuals to space and changes their daily routine as well. In a similar perspective, Ozkul (2013) discusses possibilities in representations, geo-tagged, and shared information within a network. As she concludes, locational information improves the social attachment of the places as well as creates a new representation of urban space.

Consequently, LBM is now recognized as part of the urban spatial experience of different dimensions. A direct implication of these studies is that they conceptualize the impact of location-based media usage while physically being in that location. However, parallel with Castells's theory of "space of flows", without being physically there, it can be suggested that it is still possible to receive the locational information 
The City Experience with Location-Based Media: An Examination Through Cognitive Mappings

and being aware of the space. In order to contribute to the literature from this perspective, the present paper aims to investigate the humanspace interaction created by the use of LBM without including physical experience. Using the two original qualitative studies of the case study, it was examined whether a city could be visited by LBM to perform cognitive mapping and how the representations of spatial cognition could change according to the media used.

\section{THE RESEARCH}

\section{Research Material and Method}

The present paper uses qualitative methods with the outcomes of the conducted workshop. In the workshop, after a short presentation about the theoretical background, to test the hypothesis and answer the research questions, an experiment was set up in which participants were asked to use any LBM platforms and visit the city of Naples. Within two hours, they have been asked to complete their visit and create a cognitive map of their experience. After the production of cognitive maps, a two-stage study is conducted through cognitive maps of the participants attending workshop, respectively. In the first stage of the study (Part I), cognitive maps are evaluated according to the research questions, and in the second stage (Part II), questionnaire-based interviews are made to understand the participants' direct experiences. The two-stage methodology that is constructed within the workshop linking with a theoretical background also underlines the originality of the research material. The overall research structure is shown in Fig. 1 below.

Figure 1. The structure of the research.

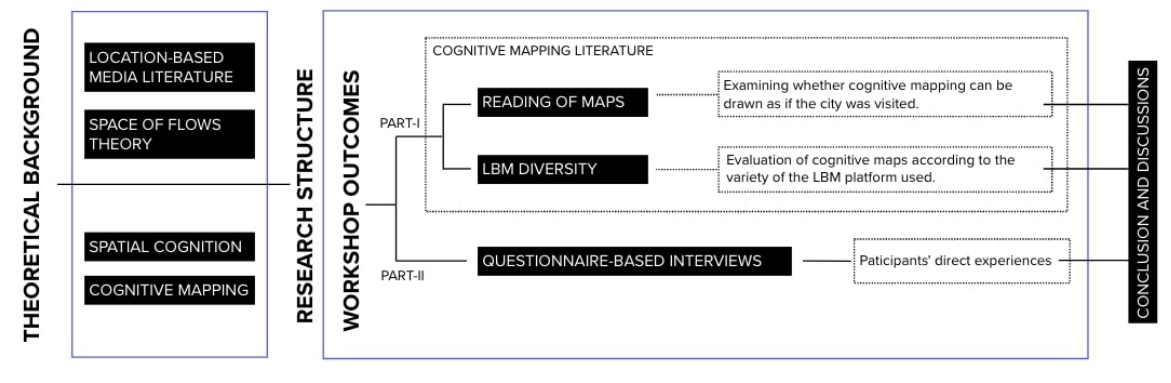

\section{Determination of Research Area}

The research data collected as a result of the workshop are planned to be personalized experience maps of the place visited through locationbased media. Therefore, the place that is expected to visit via locationbased media, must be chosen carefully. In the selection of the place to be experienced through the virtual environment, the prerequisite is that it is not physically experienced, however can be experienced virtually. The place chosen for the research question should not have been visited by the majority of the participants to test the power of location-based media influence. For this reason, the place should be chosen between the cities that fewer people have visited and have a large amount of 
locational information. In the context of these criteria, the Italian city of Naples was chosen for use in the research question.
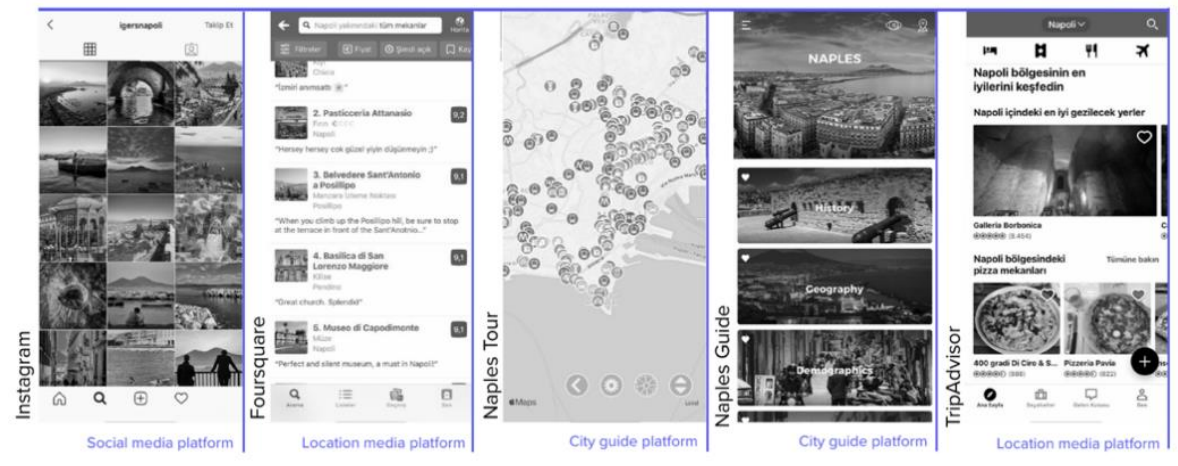

Naples is the third biggest city in Italy in terms of population as well as it is one of the oldest cities. The city is known for its many unique qualities, such as having a large historic heritage, remarkable geographic elements, unique culture, street food, and dominant cultural influence on Italian history and culture. With these qualities, Naples province is also a known tourist city. Therefore, the city has large databased of geotagged locations on the Internet (Fig. 2). On the other hand, according to the preparatory work for the workshop, it was observed that it was not visited by most participants. For this reason, the city of Naples was found suitable for cognitive mapping by visiting via locationbased media platforms, and the students who did not visit the city are selected as participants.

\section{Hypothesis}

The present paper aims to understand the effect of LBM use on spatial experience while formulates the following hypothesis:

- With the use of LBM, a city that is not actually visited can be experienced from a virtual environment. This situation can be explained by Castells's (1996) "Space of flow" theory.

- The urban experience created using LBM can be examined with the cognitive mapping method. Cognitive mapping is expected to differ according to the type and number of media tools used.

\section{Method: Cognitive Mapping with Location-Based Media}

Since this study is structured on spatial cognition studies, it is based on the cognitive representation literature. Firstly, spatial cognition literature and secondly cognitive mapping must be clarified by the known literature of leading theorists. The spatial concept is defined as a "fundamental idea of space and spatial representation" (Piaget \& Inhelder, 1967). The "spatial representation" is defined as "a mental reproduction of a sketch of an object in thought." (Laurendeau \& Pinard, 1970). These definitions conceptualize the external representation of
Figure 2. The city of Naples on location-based media platforms (from Instagram, Foursquare, Naples Tour, Naples Guide, TripAdvisor applications). 
The City Experience with Location-Based Media: An Examination Through Cognitive Mappings

space and cognitive understanding of space and provide a base for spatial cognition.

In the literature of spatial cognition and experience, representation of the personalized image of the spatial environments has been described as cognitive maps (Downs \& Stea, 1977). Cognitive map or cognitive mapping is a spatial cognition research method that implies map-like representations of an environment (Hart \& Moore, 1973, p. 248). Cognitive mapping is a production of code, store, recall, and decode information about the relative location (G. T. Moore, 1976; Tolman, 1932) in a form of a map-like schema (Downs \& Stea, 1977; Neisser, 1982). The function of cognitive maps is to structure the central aspect of spatial behaviour (Downs \& Stea, 1977; Lang, 1987). Passini (1984) determines the role of cognitive maps as an ability to represent the environment determined by a person's experience. Because of these features and their intense influence on the literature, cognitive mappings form the basis of spatial cognition studies.

As the representation of mental modal, the cognitive maps are known to be "a picture in the head" (Blackmore, 2003), "a mental process of spatial information" (Kitchin \& Blades, 2002), or as (Lynch, 1960) used, simply sketch maps. Downs \& Stea (1977) state that a cognitive map is not necessarily a "map" but using the term is a functional analogue. Lynch (1960) also suggests that people have different layouts of the cities so that it is impossible to expect replicas of reality as the maps. Contrarily, Jon Lang states that cognitive maps are "models of reality". With these features, cognitive mappings provide four types of information: recognition, prediction, evaluation, and actions (Kaplan, 1973). Although Kaplan (1983)'s suggestion of the layout of the maps appears in most of the mapping, cognitive mappings differ from person to person as well as task to task. In this sense, cognitive mappings can be used in different research as a methodology of spatial cognition tasks.

It is seen that this cognitive representation of spatial behaviour and experience is used largely in past literature. Cognitive mapping is used both in environmental behaviour literature and LBM impact research. Also, the studies about the digitalization of the urban space (AlKodmany, 2001; Dodge \& Kitchin, 2001; Kwan, 2001), are influenced by the spatial knowledge of cognitive mapping which has developed by Lynch (1960). Among these studies, using LBM and cognitive mapping together Ozkul suggests that location-based media contribute to individuals' personal storytelling (Ozkul, 2013; Ozkul \& Gauntlett, 2014). The fundamental result in her research with cognitive mappings is that participants imagined themselves in a place they represent "virtually" because of location-based media usage. The existence of these studies suggests that traces of the spatial experience can be analysed with the cognitive mapping method. In order to test the hypothesis, based on the strong methodological relation between the cognitive mapping and LBM impact, the collected data of cognitive mappings is analysed in the next chapter. 


\section{Part I. Cognitive Mapping of "Virtual City Visit" Data collection process}

In this part of the research, the data collection process is determined based on the production of the workshop's cognitive maps. The given research question for the participants was "Visit the city and draw your virtual experience on given sheets". The sheets were designed to note the information of "links, images, cultural symbols, landmarks/ icons, activities, density, places, transformations" and list LBM applications used during the process. In order to understand the role of LBM in spatial experience, the cognitive mappings prepared by the participants were subjected to two different analyses:

I. Examining whether cognitive mapping can be drawn as if the city was visited.

II. Evaluation of cognitive maps according to the variety of the LBM platform used.

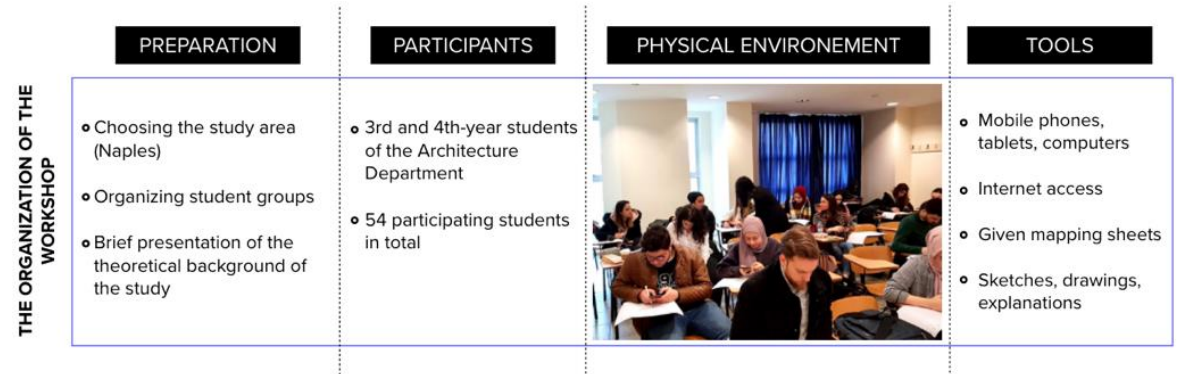

The workshop, which was held with a participant group consisting of 3rd and 4th-year students of the Architecture Department of Istanbul Kultur University (Fig. 3), was held with the participation of 54 students in two sessions. After a short presentation of the subject to the participants, previously prepared cognitive mapping sheets were distributed. Participants were asked to visit Naples via the LBM platform they wanted and fill these sheets.

During the workshop, the participants were experiencing the city via photos, tags, explanation texts, street-views, videos, etc., and they were taking notes of their experience and the sources. Thus, participants were aware of the influence of media platforms and followed their own steps of the "visit" during the process of virtual experience. After the virtual tour and cognitive mapping process, the spatial cognition of the virtually visited city was reflected in the sheets as sketches, drawings, and explanations.

\section{Is it possible to visit another city with LBM?}

In order to check whether the cognitive maps obtained from the workshop reflect the spatial experience of the participants in terms of content and form, they were compared with the cognitive mapping topologies presented by Donald Appleyard (1970) (Fig.4). In terms of language, it has been divided into two basic categories, "sequential" and
Figure 3. The organization of the workshop. 
The City Experience with Location-Based Media: An Examination Through Cognitive Mappings

"spatial", and sub-patterns of these categories. The fact that similar patterns were obtained at the end of the workshop means that the city can be visited spatially.
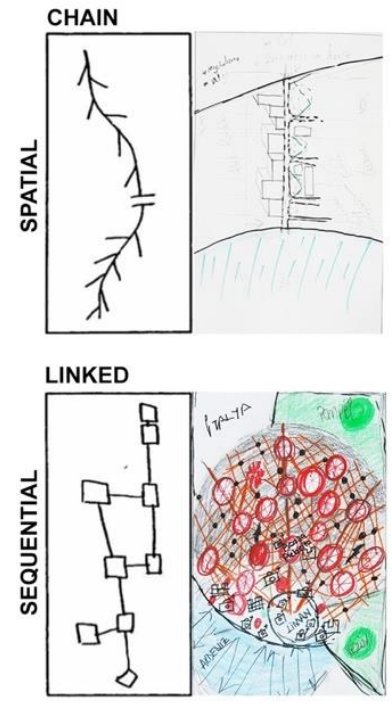

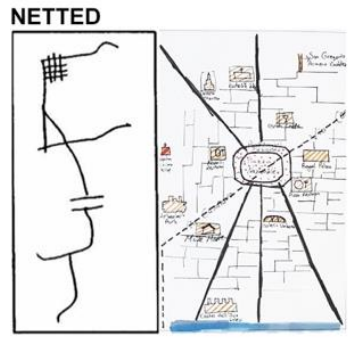

PATTERNED

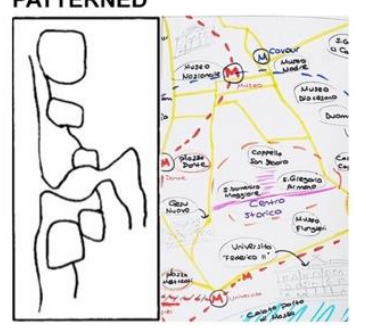

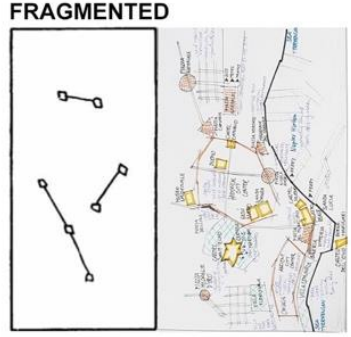

SCATTERED

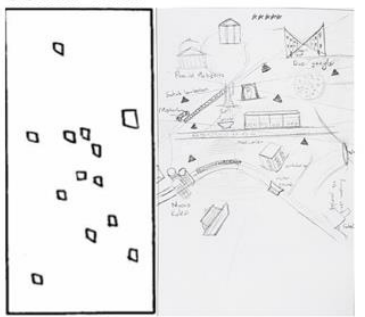

When the outputs of the workshop were evaluated, it was seen that the majority of the participants were able to create cognitive maps. As a result of the study, it was observed that most of the participants were able to "almost" visit a city that they had never visited and physically experienced, due to the correct use of the representation and location information of digital tools. As Fig. 4 reveals, despite not leaving the classroom for a minute, they have represented spatial cognition of their experience of the city of Naples, as they would represent if they were there, by using their mobile devices. Although all participants did not have the same ability to analyse location data accurately, conduct digital research, and represent the urban experience on paper, they showed that space can be experienced by roaming on networks.

Personalized expressions and representations in cognitive mapping also prove to us that the phenomenon of space now possesses so much position information that it can be experienced over the network. All these inferences reveal that a "flow" as Castells (1996) described, is possible with the help of location data that can be accessed from anywhere.

\section{How do LBM platforms differentiate cognitive maps?}

Based on the results of the study, the following inference can be made: The different information articulated to the virtual layers of the city through LBM platforms enriches the cognitive maps of the participants. The location information embedded in the virtual space of the city instantly transmits a large amount of data about the daily life of the city to the network. Therefore, "readable" and "writable" urban narratives 
(De Souza e Silva \& Frith, 2010) over the LBM platforms differentiate cognitive maps by playing a role in shaping spatial cognition.

In this context, it can be seen from cognitive mapping that users of different media platforms read the city through different focal points. In a sense, the diversity in cognitive maps reveals the power of LBM in different representations. As can be seen in Fig. 5, different media platforms highlight different urban phenomena in the mental process. The most conspicuous example of this, although the Google Maps application is used by almost all participants, the variety of other applications they use subsequently changed in their representations.

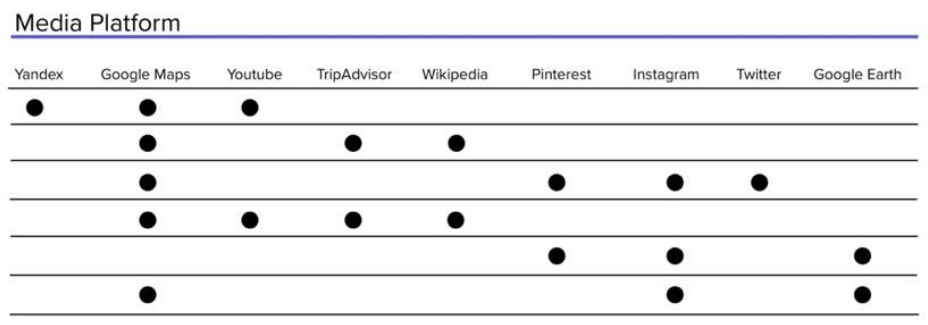
Mapping Activity
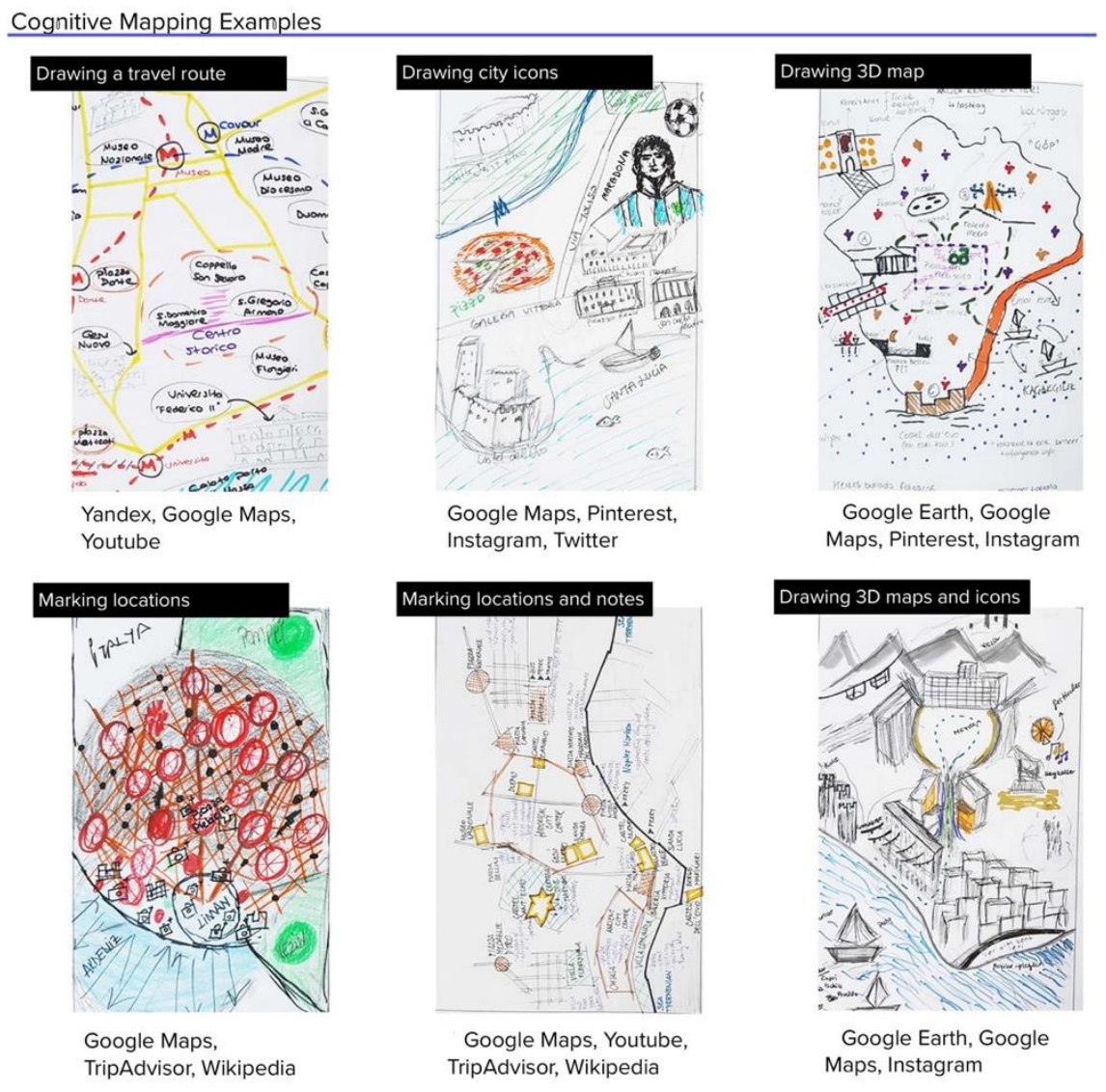

Along with mapping applications, it is seen that the participant, who has examined the travel programs on YouTube, draws a route in his mapping. The participant, who said that he used popular applications such as Instagram, Pinterest, and Twitter besides Google Maps, placed cultural figures and known icons of the city on the map of the city. This situation emerged as a three-dimensional mapping in the participant
Figure 5. Various examples of cognitive maps are produced depending on the use of different media platforms. 
The City Experience with Location-Based Media: An Examination Through Cognitive Mappings

who has used Google Earth application instead of Google Maps. Participants who use only information-based platforms such as TripAdvisor and Wikipedia in their study, besides the mapping program, have marked locations or have taken notes on the two-dimensional maps they have drawn. On the other hand, it is seen that the participant who uses Instagram, a social media platform that is based on visuality, besides mapping, filled his map with three-dimensional drawings.

\section{Part II: Structured Questionnaire-Based Interviews Data collection process}

The following stage of the research is conducted through structured questionnaire-based interviews. To do so, the outcomes of the cognitive maps results, and research questions are evaluated in collaboration with the verbal explanations/answers of the participants. In order to have the detailed information, the following questions are determined to be directed to the participants:

- What were the struggles that you have while comprising the cognitive maps?

- What did you concentrate on mostly about the research topics?

- Which social media platforms were more beneficial?

- Do you feel that you know the city now after the workshop?

- How was the experience of space? Did you feel that you were visiting the space, or did it feel like it is far away from being inside?

- Was the research part or the transfer of information part of the workshop more difficult?

The questions are asked to all the participants resulting in an overall evaluation. Starting with the first question, the investigation of being inside virtual space and its struggles are examined. The answers are noted in each interview and the featured and highlighted topics are classified. The interview answers reveal the direct experiences of the participants.

\section{Findings of the interviews reflecting direct experiences}

The expression of each participant about their personal experiences in the workshop points out the findings relating to the research topics. The first question was to examine the possibility of experiencing a city that has not been physically visited through location-based technologies. Most of the participants define that trying to understand a city within a digital platform was difficult since the flow is inside many different media applications, the collaboration of the information is not an easy thing to match.

"There were many struggles while flowing inside the space. Organizing the gained information was difficult" (Participant,17).

While experiencing the virtual city, since the topics given to the participants are searched through different media platforms, some titles 
become prominent. This finding shows that the used media interface orients the participants resulting in an "oriented experience". Some of the participants talk about the castle and seaside in which the landmarks or important points are focused mostly. Another direction was examining the commonly visited places such as restaurants, or sightseeing places. The oriented experience of virtual space also makes the cognitive mapping process difficult.

The second question depends on how the spatial perception of a city visited with location-based media can be visible in cognitive mapping. The findings show that since the limited time is given to the participants, they end up selecting images, and photographs in visual platforms. Participants also use maps in order to get the reference for their personal cognitive maps. The texts such as blogs, photo comments, travel posts, and user comments are used to develop a deeper experience in the virtual visit.

"I have searched the comments of the people who walk through the castle. The texts say so much about the place and experience. They reflect the initial-detailed personal experience of space" (Participant,15).

The experience of space is differentiated according to the participants. Some expressed strictly that the experience is low and missing while pointing spatial sense is necessary. One of the participants determined that he/she did not feel actually being there but felt like wanting to visit there. This is also an interesting expression that the flow constitutes an "inviting experience" for the participants.

"At the end of the process, I felt that the experience was left unfinished. I learned about what activities I can do if I go to that space. Feeling like being a tourist - gaining information about the space. But the virtual journey provided a flow - within the technology the space I envisioned in my mind has become familiar" (Participant, 2).

Lastly, the media tools shape the experience while understanding the limitations of the media-based orientations. Interview findings show the media tool selection is influential yet varies from person to person. It is seen that if the tool is "user-friendly", the limitations minimize, and the cognitive mapping process becomes more detailed. In addition, the venue selected for the virtual city experience is very determinant. The urban cognition depends on "the character of the selected venue/city" and the information gained from the LBM can differentiate. The city image represented in the media platforms are visually oriented and this affects the participants' spatial cognition through images while other media platforms including texts reflect first-hand experiences of other media users. The overall idea of the interview participants deals with the same difficulty of this limitation that the search was generally easy in LBM however, the re-presentation of the varied information was hard. 
The City Experience with Location-Based Media: An Examination Through Cognitive Mappings

\section{Discussion on Overall Findings}

In order to find out whether LBM offers a visiting experience and which media affect this experience, Part-I focused on cognitive maps' examination. Part-II where questionnaire-based interviews were conducted, focused on the participants' comments on the virtual city visit. Although the two investigations have their own conclusions, comparing the outputs and analysing them in the context of general results will help to contribute to the LBM studies. Figure 6 summarizes the key concepts arise from Part-I and Part-II of the study.

Figure 6. Comparisons between Part I \& Part II, determining the expressions.

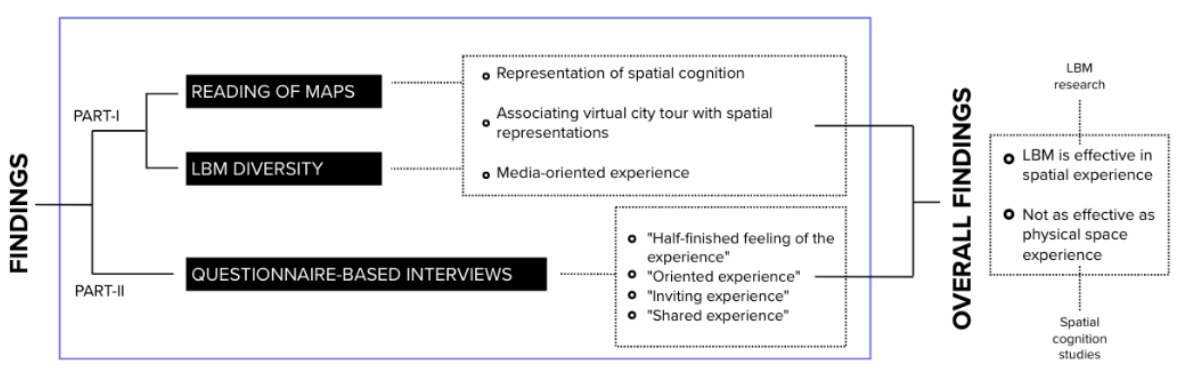

As it is summarized in Figure 6, in essence, within the investigation of the possibility to visit another city with LBM, testing the feasibility of cognitive mapping proves that an experience is realized. It is also seen as evident in the findings of Part-I that there is a strong relationship between the selection of the media platform and the representation. For instance, the usage of a map-based media platform highlights different urban phenomena in the mental process and the representations appear as drawing the city with a diagrammatical settlement scheme. These findings are considered important as they have the potential to open up the spatial experience discussions shaped by the use of media.

The summarized result in Figure 6 shows that the user interview focused on the information gained from the LBM is mostly the blurred information gained in varied contexts. The interviews reflect the experience with such expressions: "not physical, without interaction, external, no senses, partially experienced, etc.". The reason for this finding is the fact of the usage of informative technologies enables the participants to understand the general framework of the place (the location, the landmarks, the important cultural references, etc.).

Another important point in the user interview is that the spatial mobility and experience in virtual platforms can be called "shared experience" in which many people comprise their personal access. The interviews reflect that the comments and data of other users affect the virtual visit as they combine with the LBM usage. It is also essential to underline the description of "feeling like being there". Interviews emphasize the related situation with the expression of most of the participants as "feeling like walking in the city". This finding indicates 
that long-term use of LBM has the potential to create a cognitive perception close to physical space experience.

When the outputs of the interviews and the cognitive map analysis are compared, an important difference emerges. Part-I shows that a cognitive spatial experience takes place, and the media differentiate this cognitive process, while Part-II shows that the participants' experiences cannot replace the physical space experience. The combination of the two studies reveals both the potential impact of LBM use on the experience of space and its shortcomings. The overall results underline the significance of user-space interaction along with the virtual spatial flow since it is also an important issue in today's society that the social media platforms and their tools provide not only visual but also spatial access for the users.

\section{CONCLUSIONS AND RECOMMENDATIONS}

This paper explored the potential role of LBM on spatial experience in terms of spatial cognition. The intention is to find out if LBM were able to create a spatial experience of the city that never been experienced, how different LBMs might affect the spatial experience, and what type of information they can offer. The method was applied in a workshop with the contribution of participants that were tasked to visit a city through LBM and produce cognitive maps of the experience. The investigation is entirely conducted through LBM searches. Through the production of cognitive maps of participants, and two qualitative analyses, the hypothesis is examined with the collected data.

The data sets emerging from the two stages of the study were correlated and it was found that LBM's massive potential to create an impact of spatial experience and cognitive mapping is a constructive tool to test it. Furthermore, the investigation on cognitive mapping also showed that LBMs have different spatial implications on spatial cognition that differentiates the cognitive maps' layout.

Since the users are exposed to various spatial data through different platforms, the experience is quite blurred as they have described. In addition to that, the experience of others can easily transform the experience of the media user. While a place that has not been physically visited is envisioned as if it has been visited, it is very difficult to deepen the experience. However, cognitive mapping representations of the virtually experienced city can be produced, therefore we may also argue that LBM influences the spatial experience. The general outputs of this study support the view that the use of LBM constitutes a research area for cognitive space experience studies. The data obtained as a result of the interpretation of all the relationships dealt with in this study are critical for spatial cognition and environmental behaviour research. 
The City Experience with Location-Based Media: An Examination Through Cognitive Mappings

\section{ACKNOWLEDGEMENTS/NOTES}

This study is based on the workshops named "Space of Flows Concept: Cognitive Mapping Through Social Media" conducted in Istanbul Kultur University, Faculty of Architecture, Department of Architecture by the authors. Special thanks to the students for their participation in the workshop.

\section{CONFLICT OF INTEREST}

The authors declared that this study has received no conflict of interest.

\section{FINANCIAL DISCLOSURE}

The authors declared that this study has received no financial support.

\section{ETHICS COMMITTEE APPROVAL}

Ethics committee approval was not required for this article.

\section{LEGAL PUBLIC/PRIVATE PERMISSIONS}

In this research, the necessary permissions were obtained from the relevant participants (individuals, institutions and organizations) during the survey, in-depth interview, focus group interview, observation or experiment.

\section{REFERENCES}

Akgun Yuksekli, B. (2017). Yeni Medyanın Mekânsal ve Dijital Aktivizmdeki Rolü: Kent Kaşifliği Örneği. Ege Mimarlık Dergisi, Ekim, 18-23.

Al-Kodmany, K. (2001). Supporting imageability on the World Wide Web: Lynch's five elements of the city in community planning. Environment and Planning B: Planning and Design, 28(6), 805-832. https://doi.org/10.1068/b2746t

Appleyard, D. (1970). Styles and methods of structuring a city. Environment and Behavior, 2, 100-117. https://doi.org/10.1177/001391657000200106

Blackmore, S. (2003). Consciousness: An Introduction. Hodder \& Stoughton. https://www.amazon.co.uk/Consciousness-IntroductionSusan-J-

Blackmore/dp/019515343X/ref=sr_1_1?s=books\&ie=UTF8\&qid=15425 $39329 \& \mathrm{sr}=1-1 \&$ keywords $=019515343 \mathrm{X}$

Castells, M. (1996). The Rise of the Network Society. Blackwell. https://doi.org/10.4337/9781845421663.00029

De Souza e Silva, A. (2006). From cyber to hybrid. Space and Culture, 9(3), 261-278. https://doi.org/10.1177/1206331206289022

De Souza e Silva, A., \& Frith, J. (2010). Locational privacy in public spaces: media discourses on location-aware mobile technologies. Communication, Culture \& Critique, 3(4), 503-525. https://doi.org/10.1111/j.1753-9137.2010.01083.x

De Souza e Silva, A., \& Hjorth, L. (2009). Playful urban space: a historical 
approach to mobile games. Simulation and Gaming, 40(5), 602-625. https://doi.org/10.1177/1046878109333723

De Souza e Silva, A., \& Sutko, D. M. (2010). Location-aware mobile media and urban sociability. New Media and Society, 13(5), 807-823. https://doi.org/10.1177/1461444810385202

De Souza e Silva, A., \& Sutko, D. M. (2011). Theorizing locative technologies through philosophies of the virtual. Communication Theory, 21(1), 23-42. https://doi.org/10.1111/j.1468-2885.2010.01374.x

Dodge, M., \& Kitchin, R. (2001). Mapping Cyberspace. Routledge. https://doi.org/10.4000/cybergeo.881

Downs, R. M., \& Stea, D. (1977). Maps in Mind: Reflections on Cognitive Mapping. Harper \& Row. https://doi.org/10.4324/9780203789155-10

Evans, L. (2014). Being-towards the social: mood and orientation to location-based social media, computational things and applications. New Media and Society. https://doi.org/10.1177/1461444813518183

Evans, L. (2015). Locative Social Media: Place in the Digital Age. Palgrave Macmillan. https://doi.org/10.1057/9781137456113

Frith, J. (2014). Communicating Through Location: The Understood Meaning of the Foursquare Check-In. Journal of Computer-Mediated Communication, 19(4), 890-905. https://doi.org/10.1111/jcc4.12087

Gordon, E., \& de Souza e Silva, A. (2011). Net Locality: Why Location Matters In A Networked World. Oxford: Wiley-Blackwell Publishing. https://doi.org/10.1002/9781444340679

Hart, R. A., \& Moore, G. T. (1973). The Development of Spatial Cognition: A Review. In R. M. Downs \& D. Stea (Eds.), Image \& environment: Cognitive mapping and spatial behavior (pp. 246-288). Aldine Transaction. https://doi.org/10.4324/9780203789155-26

Humphreys, L. (2007). Mobile social networks and social practice: a case study of Dodgeball. Journal of Computer-Mediated Communication, 13(1), 341-360. https://doi.org/10.1111/j.1083-6101.2007.00399.x

Humphreys, L. (2010). Mobile social networks and urban public space. New Media and Society, 12(5), 763-778. https://doi.org/10.1177/1461444809349578

Humphreys, L., \& Liao, T. (2013). Foursquare and the parochialization of public space. First Monday, 18(11). https://doi.org/10.5210/fm.v18i11.4966

Iavarone, A. H., \& Dursun Çebi, P. (2019). The Urban Space of Network Society: Digital Flaneurs in the Age of Social Media. Livenarch International Congress, September.

Kaplan, S. (1983). A Model of Person-Environment Compatibility. Environment and Behavior, 15(3), 311-332. https://doi.org/10.1177/0013916583153003

Kitchin, R., \& Blades, M. (2002). The Cognition of Geographic Space. I. B. Tauris. https://doi.org/10.5040/9780755620951

Kut, S., Aydınlı, S., \& Erdem, A. (2013). Sibertektonik mekân. Tasarım + Kuram, 9(15), 21-34. https://doi.org/10.23835/tasarimkuram.240908 
The City Experience with Location-Based Media: An Examination Through Cognitive Mappings

Kwan, M. P. (2001). Cyberspatial cognition and individual access to information: the behavioral of cyber geography. Environment and Planning B: Planning and Design, 28, 21-37. https://doi.org/10.1068/b2560

Lang, J. (1987). Cognitive Maps and Spatial Behavior. In J. Lang (Ed.), Creating Architectural Theory: The Role of the Behavioral Sciences in Environmental Design (pp. 135-144). Van Nostrand Reinhold.

Laurendeau, M., \& Pinard, A. (1970). The development of the concept of space in the child. International Universities Press. https://doi.org/10.1192/bjp.119.552.565-b

Lynch, K. (1960). The Image of the City. Cambridge, Mass: MIT Press.

Moore, G. T. (1976). Theory and research on the development of environmental knowing. In G. Moore \& R. G. Golledge (Eds.), Theories, research, and methods (pp. 138-164). Stroudsburg, PA. https://doi.org/10.1177/0013916579111002

Neisser, U. (1982). Memory observed: Remembering in natural contexts. W. H. Freeman and Co. https://doi.org/10.1080/00029157.1984.10402579

Ozkul, D. (2013). You're virtually there: Mobile communication practices, locational information sharing and place attachment. First Monday, 18(11). https://doi.org/10.5210/fm.v18i11.4950

Ozkul, D., \& Gauntlett, D. (2014). Locative media in the city: Drawing maps and telling stories. The Mobile Story: Narrative Practices with Locative Media Technologies, January, 113-127. https://doi.org/10.4324/9780203080788

Passini, R. (1984). Wayfinding in architecture. Van Nostrand Reinhold.

Piaget, J., \& Inhelder, B. (1967). The Child's Conception of Space. W.W. Norton.

Saker, M., \& Evans, L. (2016a). Everyday life and locative play: an exploration of Foursquare and playful engagements with space and place. Media, Culture \& Society, 38(8), 1169-1183. https://doi.org/10.1177/0163443716643149

Saker, M., \& Evans, L. (2016b). Locative mobile media and time: Foursquare and technological memory. First Monday, 21(2). https://doi.org/10.5210/fm.v21i2.6006

Saker, M., \& Frith, J. (2018). Locative Media and Sociability: Using Location-Based Social Networks to Coordinate Everyday Life. Architecture_media_politics_society, 14(1), 1-21.

Sheller, M., \& Urry, J. (2006). The New Mobilities Paradigm. Environment and Planning A, 38(2), 207-226. https://doi.org/10.1068/a37268

Tokgöz, C. (2017). Konum Tabanlı Mobil Oyunlar ve Mekan Algısı: Ingress Üzerine Etngrafik Bir Araștırma. Ilef Dergis, 4(2 sonbahar), 7-36.

Tolman, E. C. (1932). Purposive behavior in animals and men. Century/Random House.

Wilken, R. (2012). Locative media: From specialized preoccupation to mainstream fascination. Convergence, 18(3), 243-247. 
https://doi.org/10.1177/1354856512444375

\section{Resume}

A. Hilal Iavarone received her BSc. degree from Ylldiz Technical University in 2016, as the highest-ranked student. She is currently a student of ITU Architectural Design PhD program. Since 2017, she works for Istanbul Kultur University, as a research assistant. Her current research interests are media architecture correlation and design studio studies.

Esin Hasgül received her PhD degree from Istanbul Technical University, Architectural Design Program in 2018. She has been working as a lecturer at Istanbul Kultur University since 2015. Her research areas are spatial organization and wayfinding, housing design and flexibility, design guidelines, rural studies, and design. 